\title{
Sleep EEG Signatures in COVID-19 Survivors: A Facemask/ COVID-19-Induced Comment
}

\author{
Reza Rastmanesh ${ }^{1,2,3}$ (D)
}

Received: 4 November 2021 / Accepted: 13 November 2021 / Published online: 16 November 2021

(c) The Author(s), under exclusive licence to Springer Nature Singapore Pte Ltd. 2021

I read with interest the article by Goyal et al. [1]. I would like to suggest adding some useful points to their core conclusion to provide a consolidated overview for future mechanistic and comparative studies.

Authors concluded that abnormal EEG waves are very commonly seen in COVID-19 survivors and that presence of such abnormal PSG-EEG waves suggests that COVID19 might have similar effects as depression, insomnia on COVID-19 survivors, at least in short run. As they have correctly suggested, to find out whether these changes are temporary or permanent (and/or reversible), needs to be evaluated by performing serial polysomnographies in patients with COVID-19.

Here, it is crucial to notice the unrecognized role of face masks and their potential confounding effect on sleep studies and brain EEG patterns. Face mask wearing during COVID19 can impede/impair the yawning behavior in many ways [2]. Face masks can, for instance, impede mandible jaw movement in a physical manner and totally/partially obscure visibility of jaw movement during physiologic activities such as yawning and thereby can additionally inhibit contagious yawning in community settings through impairment of both face and emotion recognition [2, 3]. Face masks may exert bias through other pathways. For instance they can further induce hypoxia and hypercapnia [4], which in turn, drastically alters brain EEG patterns [5], just to mention a few.

This comment refers to the article available online at https://doi. org/10.1007/s41782-021-00174-0.

Reza Rastmanesh

r.rastmanesh@gmail.com

1 The Nutrition Society, London, UK

2 American Physical Society, Maryland, MD, USA

3 \#6, Physicians Building, Sarshar Alley, Vali Asr Street, Tajrish, 1961835555 Tehran, Iran
I argue that this very issue can substantially bias all sleeprelated studies carried out during or after the COVID-19 pandemic.

Both ontogenetically and phylogenetically, there is a pivotal link between yawning and REM sleep. A parallel curve has been demonstrated the similitude of the evolution of yawn's frequency and the amount of REM sleep [6]. Also, yawning rhythm changes the EEG [6-8]. For instance, yawing substantially alters sleep EEG slow wave activity [8]. In an experiment, people complaining of excessive sleepiness were spontaneously yawning while trying to stay awake in a quiet and darkened room. Yawning bouts were preceded and followed by a meaningful greater delta activity in EEG than movements. After yawning, alpha rhythms were reported to be significantly attenuated, decelerated, and shifted toward central brain regions [7].

These comments apply not only to the paper by Goyal et al. [1] but more generally to "all" studies investigating sleep studies since the appearance of COVID-19. A full citation of all the publications and all the pathways and mechanisms by which altered yawning rhythm may confound sleep studies are beyond the scope of this letter, due to the space limits, but can be made available by the author on request.

- I take this opportunity to introduce, for the first time, a hidden bias during COVID-19 pandemic entitled "Yawning- Induced Bias" in sleep studies (such as those dealing with sleep EEG, sleep duration, sleep quality, hypersomnolence, etc.).

- To control for such a confounding effect, I further suggest that there is an urgent need to revisit threshold-free cluster enhancement and polysomnography methods during settings/events, whenever/wherever yawning behavior is altered due to any reason (including but not limited to face mask wearing).

Therefore, if COVID-19 is over, and once face mask wearing is abandoned, the situation before, vs. post 
COVID-19 pandemic will not be the same. Future (comparative and/or mechanistic) studies aiming to evaluate sleep EEG signatures by performing serial polysomnographies (or any other measures) in patients with COVID-19 should take this game-changing bias into account.

\section{Declarations}

Conflict of interest Author has no competing or conflict of interest.

\section{References}

1. Goyal A, Saxena K, Kar A, Bhagtana PK, Sridevi CSKR, Chaudhary S, Ali R. Sleep EEG signatures in COVID-19 survivors. Sleep Vigil. 2021;5:147.

2. Gori M, Schiatti L, Amadeo MB. Masking emotions: face masks impair how we read emotions. Front Psychol. 2021;12:669432.

3. Saeidi R, Huhtakallio I, Alku P (2016) Analysis of face mask effect on speaker recognition. In: Conference proceeding. Interspeech, p 1800-1804
4. Strapazzon G, Gatterer H, Falla M, Dal CT, Malacrida S, Turner R, Schenk K, Paal P, Falk M, Schweizer J, Brugger H. Hypoxia and hypercapnia effects on cerebral oxygen saturation in avalanche burial: a pilot human experimental study. Resuscitation. 2021;158:175-82.

5. Wang D, Yee BJ, Wong KK, Kim JW, Dijk DJ, Duffin J, Grunstein RR. Comparing the effect of hypercapnia and hypoxia on the electroencephalogram during wakefulness. Clin Neurophysiol. 2015;126:103-9.

6. Walusinski O. Yawning: from birth to senescence. Psychol Neuropsychiatr Vieil. 2006;4:39-46.

7. Guggisberg AG, Mathis J, Herrmann US, Hess CW. The functional relationship between yawning and vigilance. Behav Brain Res. 2007;179:159-66.

8. Opp MR, Obal F Jr, Krueger JM. Effects of alpha-MSH on sleep, behavior, and brain temperature: interactions with IL 1. Am J Physiol. 1988;255:R914-22.

Publisher's Note Springer Nature remains neutral with regard to jurisdictional claims in published maps and institutional affiliations. 